\title{
EFFECT OF ANNEALING TEMPERATURE ON PHYSICAL PROPERTIES Of INDIUM DOPED CADMIUM OXIDE THIN FILMS
}

\author{
Jinan A. Abd ${ }^{1}$, Enas M. Al-Robayi ${ }^{2}$, Zainab J. Shanan ${ }^{3}$, Nadir F. Habubi ${ }^{4}$ \\ ${ }^{1,2}$ laser Physics Department, College of Science for Women, University of Babylon, Iraq. \\ E-mail: jinanali7077@yahoo.com \\ E-mail: dr.enas17@yahoo.de \\ ${ }^{3}$ Physics Department, College of Science for Women, Baghdad University, Iraq. \\ E-mail: zainabjassim73@yahoo.com \\ ${ }^{4}$ Physics Department, College of Education, Al-Mustansiriyah University, Iraq. \\ E-mail: nadirfadhil@yahoo.com
}

\section{ABSTRACT}

Nanostructured indium doped $\mathrm{CdO}$ thin films were prepared by spray pyrolys is on glass substrate and annealed at 200$400{ }^{\circ} \mathrm{C}$ for 1 hour. The structural, optical, and electrical properties of prepared films were studied using different techniques such as optical transmission, photoluminescence, X-ray diffraction, and Hall measurement. X-ray analys is shows that the In doped $\mathrm{CdO}$ films are preferentially orientated along (111) crystallographic directions. Increasing of annealing temperature increases the films packing density and reorient the crystallites along (111) plane. The optical transmissions of all annealed films decreased with increasing annealing temperature. An increasing in the absorbance and photoluminescence spectra with increasing annealing temperature was denoted in all films. The band gap value of $\mathrm{CdO}: 4 \% \mathrm{In}$ equals to $2.5 \mathrm{eV}$ and it decreases with annealing temperature and reaches of $2.45 \mathrm{eV}$ for $400^{\circ} \mathrm{C}$. The res is tivity of annealed films decreased as annealing temperature increased. While high conductivity achieved in the present study is found to be $11.37 \times 10^{2}(\Omega . \mathrm{cm})^{-1}$ for annealing at $400^{\circ} \mathrm{C}$.

Keywords: Thin film; Annealing; Structural properties; CdO; CdO:In; Optical properties; Hall measurements.

\section{Council for Innovative Research}

Peer Review Research Publishing System

Journal: Journal of Advances in Chemistry

Vol. 11, No. 4

editorjaconline@gmail.com

www.cirjac.com 


\section{INTRODUCTION}

Metallic oxides are a materials class showing one of the greatest range of properties -superconducting, ferroelectric, ferromagnetic [1], multiferroic, magneto-resistive, dielectric, or conducting. Of particular interest are the so-called transparent conducting oxides (TCOs). The TCOs are heavily used for flat panel dis plays, photovoltaic cells, low emissivity windows, electrochromic devices, sensors and transparent electronics [2,3]. Among the metal oxide semiconductors CdO is an n-type semiconductor and has a rock-salt structure, in which each $\mathrm{Cd}$ or $\mathrm{O}$ ion is surrounded by 6 neighbors. In contrast to the other TCOs, it has a minimum optical band gap of about 2.2 -2.5 eV [4]. CdO has high electrical conductivity and optical transmittance in the visible region of the solar spectrum. Due to these properties of $\mathrm{CdO}$, it is one of the promising TCO from II to VI group of semiconductors. CdO films have been prepared so far by many different methods which are chemical bath deposition (CBD) [5], pulsed laser deposition [6], sol-gel [7], magnetron sputtering [8], metal-organic chemical vapor deposition [9], and successive ionic layer adsorption and reaction (SILAR) methods [10].

When these various oxides are doped with donors, the free electrons lie in the lowest conduction band. The next available empty state after this is not the conduction band minimum itself, but higher unoccupied conduction states. This increases the energy of the lowest optical transition, the optical gap. This is the Moss -Burstein shift, and varies inversely with the effective mass [11]. Indium has been used as a suitable dopant for transparent conducting films to increase the concentration of conduction electrons and improve the electrical conductivity. The dopant In ions in CdO film can either enter into the crystalline structure of $\mathrm{CdO}$ existing mainly in substitutional state or adsorbed in grain boundary regions. Since In ions substituting $\mathrm{Cd}$ ions in Cd lattice can liberate more conducting electrons in the conduction band, the increase of In concentration to certain level can significantly enhance the concentration of electrons and hence the carrier concentration [12].

In this work spray pyrolys is technique has been used to prepare CdO:4\% In films because it is simple, cost effective and suitable for large area thin films preparation with homogenous doping level [13] which are attractive for photoelectronic devices. Also we reported the effect of annealing temperature on structural, optical, and electrical properties of In doped CdO thin film.

\section{EXPERIMENTAL}

Spray pyrolysis deposition technique was used to prepare $\mathrm{CdO}: 4 \%$ In thin films on glass substrates. An $0.1 \mathrm{M}$ solution of cadmium acetate $\mathrm{Cd}\left(\mathrm{CH}_{3} \mathrm{COO}\right)_{2} \cdot 2 \mathrm{H}_{2} \mathrm{O}$ diluted with methanol and water in ratio 1:1 was used to prepare CdO solution. CdO:In thin films were prepared by doping $\mathrm{CdO}$ solution in ratio(4\%) of $\operatorname{lnCl}_{3}$ and water mixture with $0.1 \mathrm{M}$. The deposition parameters were: The distance between the nozzle and the substrate was maintained at $31 \mathrm{~cm}$, the substrate temperature of $350^{\circ} \mathrm{C}$ was controlled within $\pm 10^{\circ} \mathrm{C}$ by using an iron-constant themocouple, nitrogen gas with a pressure of 4 bar, spray time $(7 \mathrm{~s})$ and the spray interval $(70 \mathrm{~s})$. The thicknesses of the films were measured to be $234 \mathrm{~nm}$ using Michlson Interferometer. The chosen films were annealed to $\left(200,300\right.$, and $\left.400{ }^{\circ} \mathrm{C}\right)$ for 1 hour. The annealed films were characterized for their physical properties using the appropriate techniques. The crystalline structure of the films was confimed by X-ray diffraction (XRD) with $\mathrm{Cu}$ Ka radiation (Rigaku Model, $\lambda=1.5406 \mathrm{~A}^{\circ}$ ). The accelerating voltage of 40 $\mathrm{kV}$, emission current of $30 \mathrm{~mA}$ and the scanning speed of $2^{\circ}$ per min were used. The transmittance and absorbance spectra for all films were recorded by (UV/VIS, Cecil ,Cez200,7000Series, Metertec). The photoluminescence spectrum of all films was recorded by Hitachi F-2500 FL Spectro-photometer.

\section{RESULTS AND DISCUSSION}

\subsection{Structural Properties}

Figure 1 shows the X-ray diffraction (XRD) patterns of the prepared CdO and CdO: 4\%ln films . For the asdeposited films, the XRD peak associated with the (111), (200), (220) planes of the cubic structure (JCPDS Card No:050640) [14] are observed. The (111) plane of the CdO crystal grew more predominantly than the other planes, and its intensity increased with doping and annealing. The shift in the preferential orientation of the XRD peaks due to the incorporation of some of the cations and various deposition conditions were also reported by earlier workers [15,16]. When annealing increases from $200^{\circ} \mathrm{C}$ to $400^{\circ} \mathrm{C}$, the crystallite size also increases from $42.8 \mathrm{~nm}$ to $74.3 \mathrm{~nm}$. The intensity of the diffraction peak was also found to increase with increasing annealing temperature and get sharper with decreasing full width half maximum (FWHM). This can be attributed to the improvement in crystallinity of CdO:4\% In thin films. The structural parameters of annealed and unannealed $\mathrm{CdO}: 4 \%$ In thin films are given in Table 1.

For all films, the grain size (D) was calculated from the full width at half maximum (FWHM) ( $\beta$ ) of the preferential orientation diffraction peak by using the Scherrer equation [17]:

$$
\mathrm{D}=\frac{k \cdot \lambda}{\beta \cdot \cos \theta}
$$

Where $k$ denotes the Scherrer constant (the shape factor of the average crystallite and can be considered $k=0.90, \lambda=$ $1.5406 \AA$ is the wavelength of the incident Cu Ka radiation. 

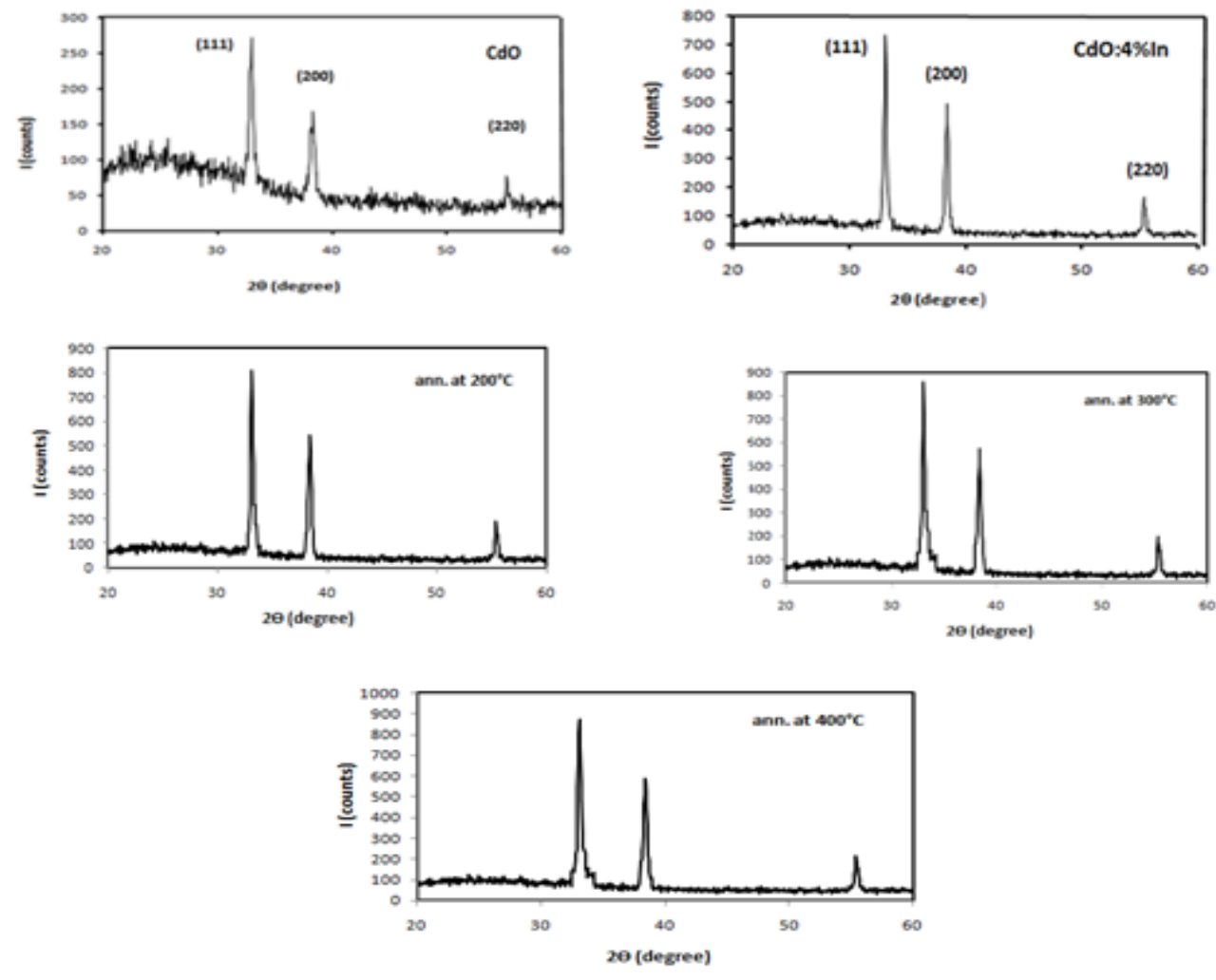

Fig. 1: The X-ray diffraction (XRD) patterns of $\mathrm{CdO}$ and $\mathrm{CdO}: 4 \% \mathrm{dn}$ films annealed at 200,300 and $400{ }^{\circ} \mathrm{C}$

According to Table 1, the films have better crystallinity levels after annealing. Similar results have been reported for annealed CdO films prepared by SILAR method [18]. Additionally, to have more information on the amount of defects in the films, the dislocation density (d) was evaluated from the formula [19]:

$$
\delta=\frac{1}{D^{2}}
$$

Where $D$ is the grain size. This quantity, $\delta$, is defined as the number of dislocations intersecting a unit area of a random section. It is seen from Table 1 that the $\delta$ value of

all films is decreased with increasing annealing temperature. This means, annealing decreases the defects in the $\mathrm{CdO}: 4 \%$ In films and improves crystallite quality. This can be attributed to the improvement in crystallinity due to the regular arrangements of atoms in the crystal lattice [18].

Moreover the texture coefficient TC $(\mathrm{hkl})$ is introduced to characterize the preferential crystallite orientation along the (hkl) direction defined as [20]:

$$
\mathrm{TC}(\mathrm{hkl})=\frac{\mathrm{I}(\mathrm{hkl}) / \mathrm{I}_{\mathrm{o}}(\mathrm{hkl})}{\mathrm{N}^{-1} \sum_{\mathrm{N}} \mathrm{I}(\mathrm{hkl}) / \mathrm{I}_{\mathrm{o}}(\mathrm{hkl})}
$$

Where I (hkl), Io (hkl) and $\mathrm{N}$ are the measured relative intensity of a diffraction peak, intensity of the standard powder diffraction peak and the number of diffraction peaks respectively. The TC values of the preferential crys tallite orientation (111) of all the films were presented in Table 1. It can be observed that all the films had values larger than 1, which indicate the profusion of crystallite in a given (hkl) direction.

The calculated lattice constant for the dominant peak of $\left(\begin{array}{lll}1 & 1 & 1\end{array}\right)$ of the films is tabulated in Table 1 . However a shift in lattice constant towards its standard value $a_{0}=4.695 \AA$ [21] is observed when the films annealed from 200 to $400^{\circ} \mathrm{C}$. From Table 1, it is evident that the post annealing process improves the quality of the crystalline thin films and gives an indication that the crystallite size lie within the nanocrystal range. 


\begin{tabular}{|c|c|c|c|c|c|c|c|}
\hline Material & $\begin{array}{l}\text { Annealing } \\
\text { Temperature }\end{array}$ & $\begin{array}{l}\text { Preferentil } \\
\text { Orientation }\end{array}$ & $\begin{array}{c}\beta \times 10^{-3} \\
(\mathrm{rad})\end{array}$ & $\mathrm{TC}$ & $\begin{array}{c}\mathrm{D} \\
(\mathrm{nm})\end{array}$ & $\begin{array}{l}\delta \times 10^{-4} \\
\left(\mathrm{~nm}^{-2}\right)\end{array}$ & $\begin{array}{l}\mathrm{a} \\
(\hat{A})\end{array}$ \\
\hline CdO:4\%In & - & (111) & 4.7414 & 1.49 & 30.5 & 10.74 & 4.683 \\
\hline CdO:4\%In & 200 & $(111)$ & 3.2392 & 1,51 & 42.8 & 5.45 & 4.689 \\
\hline CdO:4\%In & 300 & (111) & 2.6347 & 1.54 & 52.6 & 3.61 & 4.692 \\
\hline CdO:4\%In & 400 & (111) & 1.8654 & 1.56 & 74.3 & 1.81 & 4.696 \\
\hline
\end{tabular}

\subsection{Optical Properties}

Optical transmittance spectra of annealed films of different temperature in the range of 300-900 nm are presented in Figure 2, measured at room temperature in air. Optical transmittance spectra of CdO thin film in a previous work [22] showed an increasing with increasing In doping up to (4\%wt.). As seen in this figure, the optical transmission of all films decreased with increasing annealing temperature. The unannealed film shows a transmittance of $78.9 \%(900 \mathrm{~nm})$ while the annealing up to $400^{\circ} \mathrm{C}$ decreases the transmittance value to $66 \%(900 \mathrm{~nm})$. On contrary of absorbance spectra of all films which exhibit an increasing in light absorption with increasing annealing temperature. This is possibly due to increase in crystalline nature and decrease in the number of defects in the localized state [23]. Hence these films can be used as optical filters and optical switches.
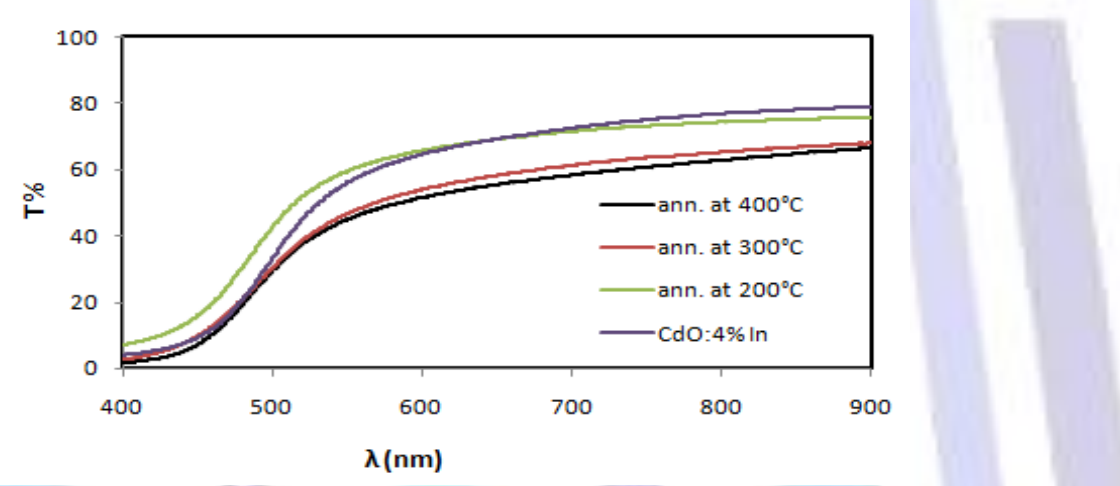

Fig. 2 : Optical transmittance spectra of $\mathrm{CdO}: 4 \%$ In films annealed at 200,300 and $400{ }^{\circ} \mathrm{C}$

Figure 3 shows the variation of the optical absorbance coefficient with wavelength. The absorption coefficient $(\alpha)$ is calculated using the equation [24]:

$$
\alpha=\ln (1 / T) / d
$$

Where $T$ is transmittance and $d$ is film thickness. The sharp increase in absorbance at the wavelength $\lambda \leq 550 \mathrm{~nm}$ is due to the inception of inter band transitions at the fundamental edge.

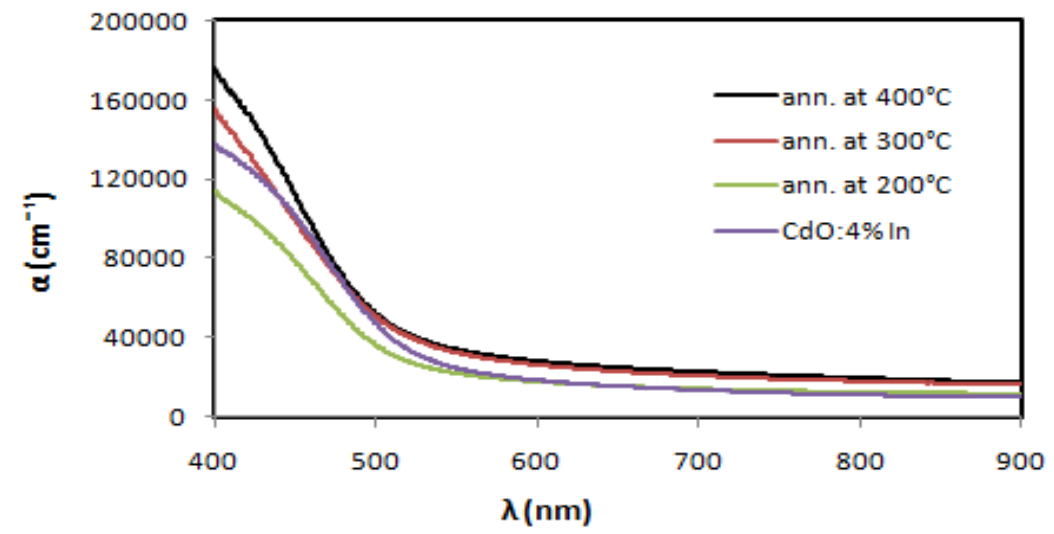

Fig. 3 : The variation of the optical absorbance coefficient with wavelength of $\mathrm{CdO}: 4 \%$ In films annealed at 200 , 300 and $400{ }^{\circ} \mathrm{C}$ 
The optical band gap values obtained by extrapolating the linear portion of the plots of $(\alpha h)^{2}$ versus (hv) to $\alpha=0$ [25] These plots are given in Figure 4. From the figure it was determined that all films have a direct band transition. It is observed that the band gap energy decreases with increasing annealing temperature. The band gap of non annealed $\mathrm{CdO}: 4 \% \mathrm{In}$ film was found to be $2.5 \mathrm{eV}$. The band gap energy was found to be $2.48 \mathrm{eV}, 2.47 \mathrm{eV}$ and $2.45 \mathrm{eV}$ for the films annealed at 200,300 and $400{ }^{\circ} \mathrm{C}$, respectively. Similar trend was also seen in films prepared by sol gel method [26]. This slightly decrease in optical band gap energy with increasing annealing temperature may be due to the increase in the carrier concentration and also may be due to sinter of the nanocrystalline and increasing in lattice parameter and grain size[27]

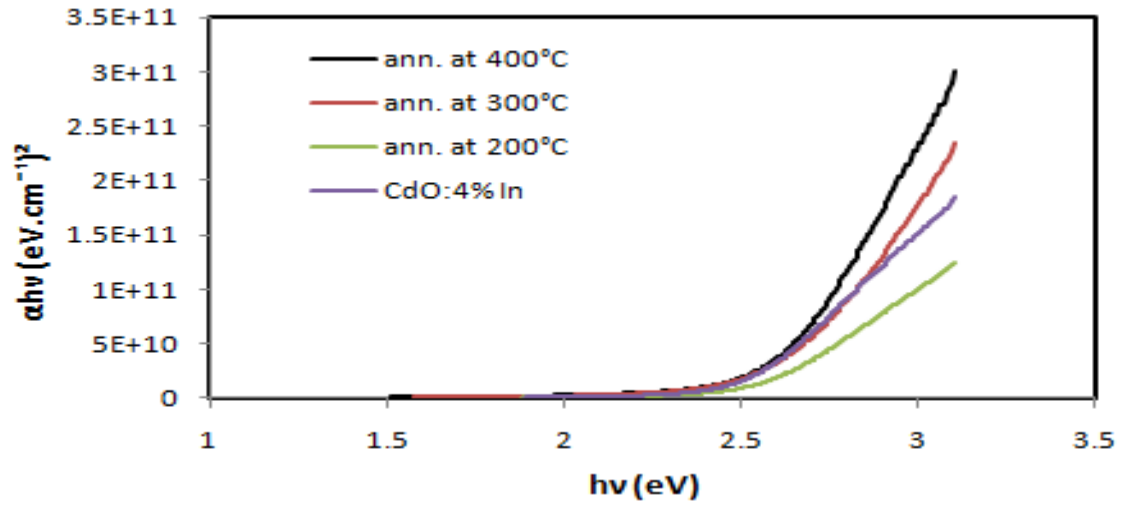

Fig. 4: The $(a h v)^{2}$ versus photon energy (hv) for CdO:4\% films annealed at 200,300 and $400{ }^{\circ} \mathrm{C}$

All the measured and calculated values of optical properties and constants of all prepared films at the fundamental edge were tabulated in Table 2. This table a show how is the annealing improves the optical properties of CdO:4\% In film. Such as the refractive index and extinction coefficient which are increased as annealing temperature increased. This trend can be attributed to the increase of optical absorption in the UV-visible region when increasing annealing temperature [28].

\begin{tabular}{|c|c|c|c|c|c|c|c|c|}
\hline \multirow{2}{*}{ Material } & \multirow{2}{*}{$\begin{array}{c}\text { Annealin } \\
\mathrm{g} \\
\text { Temp. }^{\circ} \mathrm{C}\end{array}$} & $\mathrm{T} \%$ & $\mathrm{~A} \%$ & $\mathrm{R} \%$ & $n$ & $\mathrm{~K}$ & $\alpha \times 10^{4} \mathrm{~cm}^{-1}$ & \multirow{2}{*}{$\begin{array}{l}\mathrm{E}_{\mathrm{g}} \\
\mathrm{eV}\end{array}$} \\
\hline & & \multicolumn{6}{|c|}{$\lambda=550 \mathrm{~nm}$} & \\
\hline CdO:4\%ln & - & 59.5 & 22.5 & 17.9 & 1.966 & 0.097 & 2.2191 & 2.5 \\
\hline $\mathrm{CdO}: 4 \% \ln$ & 200 & 56.1 & 25.1 & 18.8 & 2.02 & 0.108 & 2.4706 & 2.48 \\
\hline CdO:4\%In & 300 & 46.7 & 33 & 20.2 & 2.133 & 0.142 & 3.2545 & 2.47 \\
\hline CdO:4\%In & 400 & 38.9 & $\overline{41}$ & 20 & 2.156 & 0.176 & 4.0356 & 2.45 \\
\hline
\end{tabular}

(Figure 5) shows the PL spectra of the CdO:4\%In films of annealed at 200,300 and $400{ }^{\circ} \mathrm{C}$. One part can be distinguished in this spectrum which is composed of a narrow peak located at higher energies corresponding to excitonic emission $(550 \mathrm{~nm})$. This main peak is located at about $2.25 \mathrm{eV}$ and is due to an exciting bound to a donor level [29]. The intensity of unannealed film was increased as annealing temperature increased. This is may be due to improve the crystalline nature and decrease in the number of defects in the localized state.

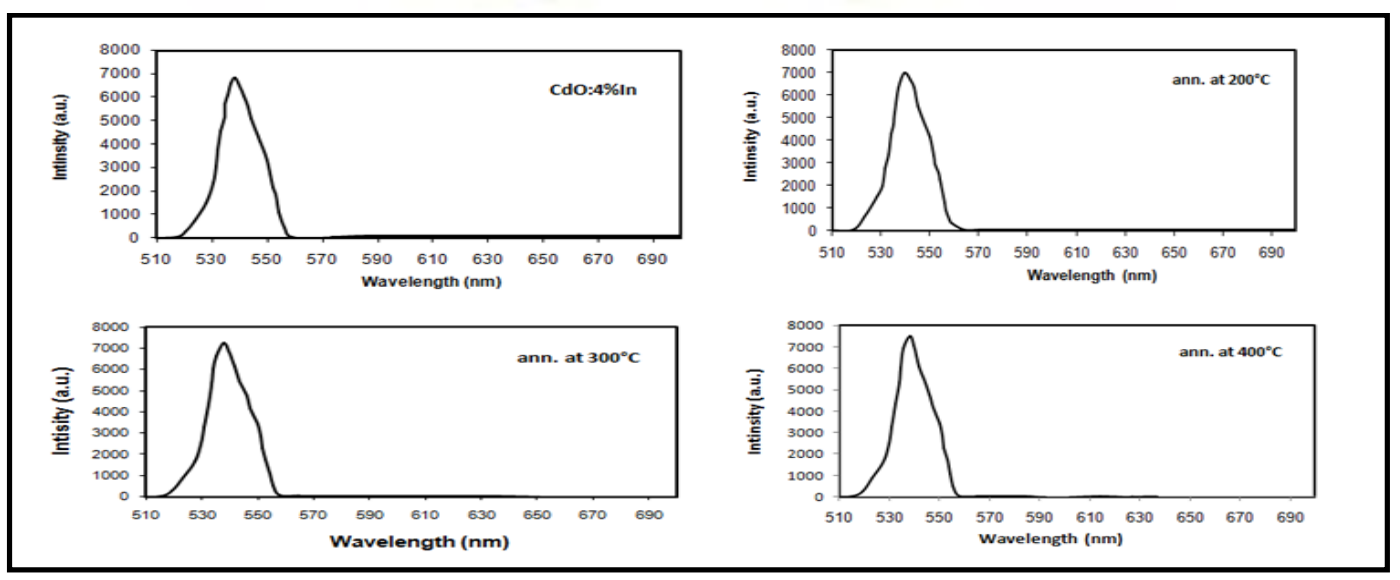

Fig. 5: Photoluminescence spectra of $\mathrm{CdO}: 4 \%$ In films annealed at 200,300 and $400{ }^{\circ} \mathrm{C}$ 


\subsection{Electrical Properties}

Hall voltage measurement was made to determine some electrical properties for un-doped and In doped samples at room temperature in a constant magnetic field of $0.55 \mathrm{~T}$. Hall constant $(\mathrm{RH})$, the conductivity $(\sigma)$, electrical resistivity $(\rho)$, carrier concentration $(\mathrm{Ne})$ and mobility $(\mu)$ have been calculated from Hall voltage and the

reported values are tabulated in Table 3. Hall measurement indicates that In-doped $\mathrm{CdO}$ are $\mathrm{n}$-type material and electrons are the majority carrier of current which results in the presence of $\mathrm{Cd}$ ion interstitials or oxygen vacancies as donors. It has been said that to achieve highly conducting thin films, the carrier concentration need to be very high. From Table 3 , it is clear, that carrier concentrations of all films increased with increasing annealing temperature. The higher carrier concentration can be attributed to the presence of both cadmium interstitials and oxygen vacancies [30]. The mobility of CdO:4\% In thin films decreases from 79.4 to $75.3 \mathrm{~cm}^{2} /(\mathrm{V} . \mathrm{s})$ as temperature increases from 200 to $400^{\circ} \mathrm{C}$. This decreasing may be due to the lattice scattering of charge carriers since the ionized impurity scattering is independent of temperature [31]. The variation of electrical conductivity $(\sigma)$ as a function of annealing temperature is shown in Figure 6 . From the figure one can observe that the conductivity of the films was found to increase with increasing annealing temperature. On contrary of resistivity and Hall constant which they decreased as annealing temperature increases, show Table 3 . These changes are resulted from the variation in $\mathrm{N}_{\mathrm{e}}$ and carrier scattering [32].

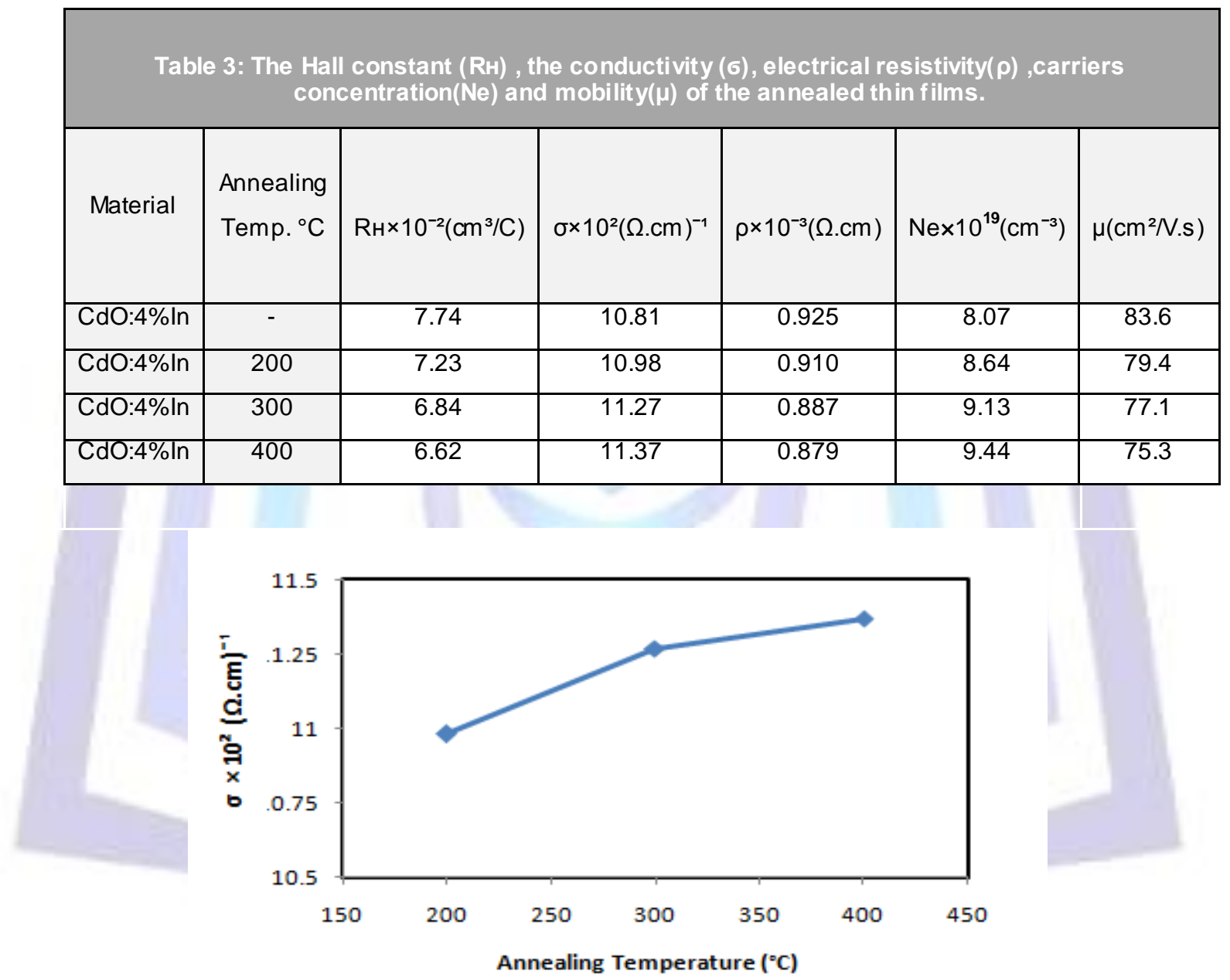

Fig. 6: The variation of electrical resistivity $(\rho)$ as a function of annealing temperature

\section{CONCLUSION}

Nanostructured CdO:4\%In thin films are prepared by means of simple and low cost spray pyrolysis method. Postannealing process helps to improve the crystalline quality of the $\mathrm{CdO}: 4 \%$ In thin films. XRD shows that the films have a cubic crystal structure. The average grain size of $\left(\begin{array}{lll}1 & 1 & 1\end{array}\right)$ orientation grains of the studied polycrystalline film annealed at $400^{\circ} \mathrm{C}$ was found to be around $74.3 \mathrm{~nm}$ and before annealed grains was found to be around $30.5 \mathrm{~nm}$. The annealing improves the optical properties of $\mathrm{CdO}: 4 \% \mathrm{ln}$ film. An increasing in the absorbance and photoluminescence spectra with increasing annealing temperature was denoted in all films. An optical transmittance spectrum shows the NIR transmittance. The unannealed film shows a transmittance of $78.9 \%(900 \mathrm{~nm})$ while the annealing up to $400^{\circ} \mathrm{C}$ decreases the transmittance value to $66 \%(900 \mathrm{~nm})$. Direct band gap of about $2.45 \mathrm{eV}$ for the film annealed at $400{ }^{\circ} \mathrm{C}$ for $1 \mathrm{~h}$. High conductivity achieved in the present study is found to be $11.37 \times 10^{2}(\Omega . \mathrm{cm})^{-1}$ for annealing at $400^{\circ} \mathrm{C}$. The carrier concentration of about $9.44 \times 10^{19}\left(\mathrm{~cm}^{-3}\right)$ and resistivity of $0.879 \times 10^{-3}(\Omega . \mathrm{cm})$ are achieved for the films annealed at $400{ }^{\circ} \mathrm{C}$ for $1 \mathrm{~h}$ which are comparable with the films prepared by using high cost physical and chemical deposition techniques . 


\section{REFERENCES}

[1] Ahn ,C. H., Triscone ,J. M., and Mannhart ,J., 2003, Nature, 424, 1015.

[2] Ginley, D. S. and Bright, C., 2000 (eds) MRS Bull , 25.

[3] Hamberg ,I. and Gramquist, C. G.,1986, J App Phys , 60, 123.

[4] Ortega, M., Santana, G, and Morales, A. A., 2000, Solid-State Electronics, 44, 10,1765-1769.

[5] Gutiérrez, L.R, Cayente-Romero, J.J., Peza-Tapia, J.M., Barrera-Calva, E., Martínez-Flores, J.C., and Ortega-López, M., Materials Letters, 2006, 60, 3866-3870.

[6] Shagnov, I.I., Kryzhanovskii,B.P. and Dubkov, V.M. , 1981, Sov. J. Opt. Technol., 48, 280.

[7] Cruz, J.S., Delgado, G.T, and Perez, R.C., 2005, Thin Solid Films, 493, 83-87.

[8] Subramanyam, T.K., Uthanna, S., and Naidu, B.S., 1998, Materials Letters, 35, 214-220.

[9] Liu, X., Li, C., Han, S., Han, J., and Zhou, C., 2003, Applied Physics Letters, 82, 1950-1952.

[10] Salunkhe, R.R. and Lokhande, C.D., 2008,Sensors and Actuators B, 129, 345-351.

[11] Hamberg, I., and Gramquist, C. G., 1986, J App Phys , 60, 123.

[12] Dakhel, A. A., 2009,Journal of Alloys and Compounds, 475, 51-54.

[13] Kumaravel, R. , Ramamurthi, K. and Krishnakumar ,V., 2010, Journal of Physics and Chemistry of Solids, 71, 15451549.

[14] JCPDS_International Centre for Diffraction Data, 1997, Card No. 05 - 0640.

[15] Jin, S. ,Yang, Y., Medvedeva, J.E., Ireland, J.R., Metz, A.W., Ni,J. Kannewurf ,C.R., Freeman , A.J., and Marks ,T.J., 2004, J. Am. Chem. Soc., 126, 13787.

[16] Koida ,T. and Kondo, M., 2007, J. Appl. Phys., 101, 0637131.

[17] Rusu ,D.I., Rusu ,G.G. , Luca, D., 2011, Acta Physica Polonica A, 119 , 850-856.

[18] . Gokul, P. M., and Sathyamoorthy, R., 2013,J. Mater. Sci. Technol., 29, 17-21.

[19] Callister W.D.1997 "Materials Science and Engineering - An Introduction", New York, John Wiley and Sons.

[20] Saleem, M. , Fang, L. , Ruan, H. B. Wu ,F., Huang ,Q. L., Xu ,C. L. , and Kong ,C. Y.,2012 International Journal of Physical Sciences , 7, 2971-2979.

[21] Khan ,M.K.R., Rahman ,M.A., Shahjahan , M., Rahman ,M.M., Hakim ,M.A., Saha , D.K. , and Khan ,J.U., Current. 2010, Appl. Phys., 10, 790.

[22] Habubi ,N. F., Al-Anssari, R. A., and Abd ,J. A., 2013, Nano Science and Nano Technology, 7(5), $172-178$.

[23] Khudiar, A.I., Zulfequar ,M., Khan ,Z.H., 2012, Mater Sci Semicond Process, 15, 536.

[24] Miao ,W., Li ,X., Zhang ,Q., Huang ,L., Zhang ,L., and Yan ,X., 2006, Thin Sold Films, 500, 70.

[25] Kose ,S., Atay ,F., Bilgin ,V. And Akyuz ,I., 2009 International Journal of Hydrogen Energy, 34, 5260 - 5266.

[26] Aksoy ,S., Caglar ,Y., llican ,S., and Caglar,M. 2009,Int. J. Hydrogen Energy, 34, 5191-5195.

[27] Abdul-Hussein K. E., Hayder M. A., and Ausama I. Kh., 2013, Journal of Materials Research and Technology, 2 , 182-187.

[28] Ziabari, A. A. and Ghodsi, F.E. 2011, Acta Physica Polonica A, 120, 536-540.

[29] Dong, J. S., 2004, Journal of the Korean Physical Society, 45, 1575-1579.

[30] Tanaka, K., Kunioka ,A., and Sakai ,Y., 1969 Jpn. J. Appl. Phys.,8 , 681-691.

[31] Yan ,M., M. Lane, Kannewurf ,C.R., and Chang R.P.H. 2001 , Appl. Phys. Lett., 78, 2342-2344.

[32] Zheng ,B.J. , Lian, J.L., Zhao, L., and Jiang ,Q., 2010, Appl. Surf. Sci., 256, 2910. 